\title{
Indivíduo e a mudança nas organizações de saúde: contribuições da psicossociologia
}

\author{
Individuals and changes in health organizations: \\ a psychosociological approach
}

Creuza da Silva Azevedo 1

Francisco Campos Braga Neto 1

Marilene de Castilho Sá 1

\footnotetext{
1 Departamento de Administração e Planejamento em Saúde, Escola Nacional de Saúde Pública, Fundação Oswaldo Cruz.

Av. Leopoldo Bulhões 1480, 7 o andar, Rio de Janeiro, $R J$ 21041-210, Brasil.
}

\begin{abstract}
The Brazilian health sector has undergone a severe crisis, affecting the case-resolving capacity, efficiency and governability of the health system as a whole and health organizations in particular. Although innovative management systems and tools have been encouraged, such innovations are limited in their ability to spawn organizational change, especially with regard to the challenge of enabling individual adherence to institutional projects and relations involving individuals and organizations. This paper focuses on the French psychosociological approach for analyzing and intervening in organizations, one of whose main thinkers is Eugène Enriquez. In its view of contemporary organizations, this approach focuses on the conflict between reproduction and creation as the main problem to be solved by management processes. While an organization is essentially seen as a place of order and repetition, organizational change implies the challenge of bringing creative individuals into the organization's project, avoiding the trap of controlling their minds and behavior.
\end{abstract}

Key words Organizational Innovation; Organizations; Psicosociology

Resumo A grave crise que o setor saúde no Brasil vem enfrentando nos últimos anos se expressa como uma crise de governabilidade do sistema e das organizações de saúde, de resolutividade e eficiência. Essa crise tem impulsionado experiências inovadoras no que se refere tanto ao desenho de novos sistemas de gestão, como ao desenvolvimento de ferramentas gerenciais. É preciso reconhecer, no entanto, os limites dessas perspectivas para subsidiar os processos de mudança organizacional, especialmente no que se refere ao desafio de gerar adesão aos projetos institucionais e à problemática da relação entre indivíduos e organizações. O presente estudo procura apresentar a contribuição da psicossociologia francesa, representada principalmente pelo pensamento de Eugène Enriquez, não só para a análise, como também para a intervenção nas organizações. Os processos de mudança têm o desafio de promover a inserção de indivíduos criativos em um projeto institucional, sem cair na armadilha do controle sutil de seus pensamentos $e$ comportamentos.

Palavras-chave Mudança Organizacional; Organizações; Psicossociologia 


\section{Introdução}

A grave crise que o setor saúde no Brasil vem enfrentando nos últimos anos se expressa como uma crise de governabilidade do sistema e das organizações de saúde, de resolutividade e eficiência. Esta crise tem impulsionado experiências inovadoras no que se refere tanto ao desenho de novos sistemas de gestão, como ao desenvolvimento de ferramentas gerenciais. Apesar de todas as dificuldades para desenvolver processos de mudança nas organizações, tais experiências têm possibilitado a democratização dos processos decisórios, o acúmulo de conhecimentos sobre a problemática específica da gestão em saúde e uma maior visibilidade dos projetos institucionais.

Essas experiências são inspiradas em duas grandes matrizes teórico-metodológicas: o enfoque estratégico de planejamento e gestão e a abordagem da gestão da qualidade total. Apesar dos avanços alcançados, é preciso reconhecer os limites dessas perspectivas para subsidiar os processos de mudança organizacional.

As duas abordagens consideram a dimensão humana presente nos processos organizacionais e reforçam os processos participativos. O enfoque estratégico, não obstante reconhecer a incerteza, aposta na possibilidade do cálculo racional sobre o comportamento humano como instrumento para mudança. A abordagem da gestão da Qualidade Total (GQT), embora reconheça a dimensão cultural na vida organizacional, limita-se a um tratamento instrumental das relações humanas nas organizações, negando inclusive o seu caráter conflitivo.

\section{A gestão da qualidade total}

Qualquer balanço que se faça sobre a difusão de novas idéias e proposições no campo das teorias administrativas durante os últimos vinte anos, sem dúvida, irá apontar a GQT como a abordagem mais bem-sucedida neste intento. Ao longo desse período, a GQT, veiculada nas versões de seus principais autores - Deming (1990), Garvin (1988), Ishikawa (1993) e Juran \& Gryna (1991), ganhou contornos de uma espécie de movimento social, cruzando todas as sortes de fronteiras: do Japão aos países ocidentais, das empresas privadas até a administração pública, da esfera estritamente industrial para organizações do setor de serviços, como saúde e educação. Difusão em tal escala, que hoje é difícil imaginar alguma organização de médio ou grande porte que não tenha experimentado ou, então, que não expresse interes- se em vir a empregar tais métodos em sua administração.

No campo específico da saúde, embora essa propagação tenha sido mais tardia e a implementação da Qualidade Total enfrente ainda dificuldades de natureza metodológica - em face do desafio da melhoria dos processos clínicos - e organizacional - em virtude da resistência e da baixa adesão em geral observada entre os profissionais médicos -, verifica-se mesmo assim um percentual bastante alto de adoção de projetos de GQT. Como ilustração, vale mencionar os sistemas de acreditação hospitalar, mecanismo já consagrado de avaliação da qualidade da assistência em saúde, que acabaram incorporando a perspectiva gerencial da Qualidade Total como base do seu processo de análise das organizações de saúde.

Evidentemente, esse boom veio acompanhado por controvérsias de diversas ordens, aqui esquematicamente separadas em dois grandes blocos. Em primeiro lugar, aparecem as críticas associadas ao acúmulo de resultados pouco expressivos quando da aplicação dos princípios, das práticas e técnicas preconizadas pela GQT. Essas evidências frustrantes contrastavam fortemente com as promessas anunciadas e as expectativas geradas em torno da GQT, servindo, em certa medida, de justificativa para o lançamento de mais uma "nova" perspectiva gerencial no início dos anos 90 - a reengenharia. De toda maneira, a reação dos teóricos e adeptos da Qualidade Total perante tais resultados foi, em geral, associá-los não propriamente a falhas ou a insuficiências do enfoque, mas meramente a problemas restritos ao processo de implementação dessas idéias, como, por exemplo: (a) o baixo engajamento das lideranças organizacionais nesse projeto; (b) o limitado esforço de treinamento de pessoal nas técnicas de trabalho em equipe ou no manuseio das ferramentas de controle estatístico de processos; (c) o curto período de desenvolvimento do programa para a maturação das mudanças organizacionais pretendidas (Hackman \& Wageman, 1995).

Um outro terreno privilegiado de discussão em torno do enfoque da Qualidade Total, de maior interesse para o presente trabalho, foi nos âmbitos teórico-conceitual e político-ideológico. Apresentada por seus apologistas como um novo e revolucionário paradigma para a gestão das organizações, teóricos da área viriam a interrogar justamente sobre a contribuição específica, em termos de originalidade e inovação, aportada pela GQT. Ou seja, questionava-se em que medida essa abordagem constituía-se de fato em uma nova filosofia geren- 
cial, com uma compreensão própria e bem fundamentada sobre o funcionamento e a gestão das organizações (Tuchi, 1997).

Já no plano político-ideológico, o debate concentrou-se em torno das proposições de empowerment e de participação dos trabalhadores no processo de mudança e de melhoria contínua da organização. Afinal, interrogavase sobre o caráter ou o sentido dessas propostas, se efetivamente libertário e emancipador, conforme advogado, ou apenas mais uma tentativa de se instrumentalizar e manipular com nova roupagem o comportamento desses trabalhadores, com vistas ao melhor desempenho das empresas.

Naturalmente, essa polêmica política e teórica em torno da GQT segue em aberto, e são inúmeras as razões para isso. O caráter assumidamente ideológico dessa discussão implica de antemão reconhecer a impossibilidade de conclusões inequívocas. De outra parte, trabalhos discutindo o valor ou o impacto da Qualidade Total apóiam-se muitas vezes em avaliações de situações e experiências organizacionais bastante particulares e radicalmente distintas, não sendo possível a generalização de suas evidências. Em verdade, estudos comparativos sobre essas iniciativas sugerem que, concomitantemente à popularização da Qualidade Total, verifica-se um fenômeno de progressiva diluição de seus conceitos e premissas, de tal sorte que, sob o rótulo de GQT, encontrar-se-iam projetos bastante diversos de mudança organizacional. A Qualidade Total, nesses casos, serviria antes de tudo como fonte de legitimação das iniciativas de mudança (De Cock \& Hipkin, 1997).

Dessa forma, seria mais pertinente discutir a Qualidade Total a partir dos seus pressupostos teórico-conceituais. Essa análise, entretanto, tampouco é de fácil consecução, já que autores como Deming (1990) ou Juran \& Gryna (1991), mais que teóricos, eram homens essencialmente práticos, sendo suas obras especificamente voltadas para dirigentes e administradores de empresas e marcadas por uma orientação essencialmente prescritiva, longe, portanto, de oferecer explicações mais estruturadas e profundas sobre os fenômenos organizacionais. Além disso, as obras desses autores, ao mesmo tempo em que apresentam pontos de vista comuns em torno dos elementos constitutivos da GQT, divergem em outras questões importantes.

Não obstante tais dificuldades, discutemse brevemente a seguir as premissas fundadoras dessa abordagem, sobretudo aquelas mais relacionadas às pessoas e à organização.
"A maior parte dos obstáculos às contribuições significativas dos trabalhadores para a melhoria da qualidade residem na filosofia, nos valores e crenças e em suas manifestações - os sistemas de controle gerencial - desenvolvidos sob a liderança de Frederick W. Taylor" (Juran \& Gryna, 1991:273).

Essa curta citação não deixa dúvidas sobre a posição crítica da GQT em face do paradigma taylorista de organização e gestão do trabalho. Seja ao propor uma outra lógica e uma nova sistemática de garantia e de melhoria contínua da qualidade, seja ao pensar mais diretamente sobre a natureza da motivação humana e sobre o processo de organização do trabalho, Deming e seus colegas afastam-se bastante dos pressupostos e das prescrições presentes na Organização Científica do Trabalho (OCT), a ponto de Schiff \& Goldfield (1995) sugerirem a existência de uma convergência de idéias entre Deming (1990) e Braverman (1980) - marxista, autor do clássico Trabalho e Capital Monopolista: A Degradação do Trabalho no Século XX.

De fato, os teóricos da GQT rejeitam o constructo do homo economicus, ser absolutamente racional, movido por estreitos interesses de ordem material e financeira. Aproximando-se da perspectiva humanista radical, esses autores consideram que o homem possui uma propensão natural de buscar aperfeiçoar-se (Sullivan, 1986). Assim, em vez da premissa do comportamento de desleixo e de boicote na atividade laboral por parte dos trabalhadores, justificativa taylorista para a instauração de um rígido sistema de controle gerencial e ainda para uma marcada separação entre o trabalho intelectual e manual, de acordo com a Qualidade Total, os empregados têm uma motivação intrínseca para o trabalho, preocupando-se com a sua qualidade e com o seu aprimoramento, cabendo à gerência justamente favorecer esse processo mediante a mudança do clima organizacional - “afastar o medo" (Deming, 1990) - e a oferta de programas de educação continuada.

A idéia de envolvimento e de participação veiculada pela GQT, por sua vez, não se resume apenas a uma espécie de aplicação defensiva e tardia da Escola de Relações Humanas (McArdle et al., 1995), representando um dos elementos nucleares do modelo de gestão proposto. Sob a ótica da Qualidade Total, o problema da qualidade de bens e serviços produzidos converte-se em uma tarefa coletiva, perpassando todas as áreas da organização e saindo das mãos de especialistas para envolver o conjunto dos seus funcionários. As ações de melhoria contínua têm por base a análise dos processos de trabalho, atividade a ser desenvolvida me- 
diante o engajamento de funcionários e gerentes em equipes interdepartamentais. Desse modo, a partir da GQT, a participação de funcionários na tomada de decisões internas, particularmente em questões relativas ao processo de organização do trabalho, é institucionalizada.

Indicados tais avanços da GQT diante principalmente do paradigma clássico e ainda dominante de gestão, é necessário, todavia, reconhecer que suas premissas não logram superar uma visão simplista e instrumental do indivíduo e da sua inserção na organização. Afinal, apesar de todas as prescrições em torno do empowerment e do estímulo à criatividade dos trabalhadores, ainda que Deming (1990) em seus princípios reporte-se à subjetividade presente nas organizações, discorrendo sobre a necessidade de se afastar o medo ou de se removerem as barreiras que privam as pessoas do justo orgulho pelo trabalho realizado (Nogueira, 1994), a Qualidade Total acaba por tomar o indivíduo como um ser passivo, pronto para introjetar as preocupações e metas da empresa e para submeter-se aos programas de melhoria de qualidade sem maiores questionamentos. Por isso mesmo, esses autores não chegam a problematizar de forma mais profunda a questão da participação. Da mesma maneira, a organização tampouco é vista como uma arena atravessada por visões de mundo e interesses conflituosos; pelo contrário, este é tomado como espaço de harmonia social.

Emergem, dessa forma, algumas contradições presentes nessa filosofia gerencial. $\mathrm{O}$ indivíduo, proclamado como elemento-chave para a organização, ao fim é concebido como uma criatura meramente funcional, desprovida de crenças, valores, desejos ou emoções, longe, portanto, de ser reconhecido como um ator político e muito menos como um sujeito singular. Nesse sentido, as propostas de participação e do estímulo à criatividade do indivíduo mostram-se claramente instrumentais, já que devem estar a serviço do alcance de melhores resultados organizacionais, sem que se ponham em questão os objetivos e a estrutura de poder dessa organização.

Ora, voltando agora à discussão inicial em torno das dificuldades e dos insucessos observados em programas de Qualidade Total, podese sugerir que uma das razões para isso encontra-se exatamente nas suas limitações teóricoconceituais ao tratar do problema do indivíduo e da organização. A exemplo de outras perspectivas gerenciais, a GQT parece assim prometer muito mais do que realmente oferece.

\section{O enfoque estratégico de planejamento}

Ao introduzir a dimensão humana e política nos processos de planejamento e gestão, o enfoque estratégico representa, sem dúvida, um rompimento com a maior parte dos pressupostos positivistas que tradicionalmente orientaram a produção teórico-metodológica e as experiências em planejamento econômico e social. Particularmente na América Latina, a crença na superioridade da racionalidade técnica para definir prioridades na alocação dos escassos recursos não resistiu ao confronto com a complexidade e a incerteza dos processos sociais e, especialmente no âmbito da gestão pública, com a baixa governabilidade das organizações.

O planejamento deixa de ser, assim, apenas uma questão de ciência e técnica. Consiste, antes de tudo, numa arte singular: "a arte de governar em situações de poder compartido" (Matus, 1993). Reconhece-se a pluralidade de atores no processo de planejamento, com diferentes capacidades (poderes) e interesses, disputando projetos e os recursos para implementálos. Planejamento e gestão deixam de dizer respeito a um "problema de administração das coisas pelos homens" e passam a significar um problema de interação entre os homens na busca de seus objetivos ou "um problema entre os homens" (Matus, 1993).

É preciso reconhecer, no entanto, que a racionalidade político-estratégica é apenas uma das formas - não a única - de expressão da dimensão humana nos processos de planejamento. E aqui parece residir uma das principais limitações desse enfoque para enfrentar os problemas que ele mesmo reconhece. Se é verdade que o sujeito do planejamento não é mais único, supostamente neutro e movido exclusivamente pela racionalidade técnica, a afirmação da pluralidade de atores e de suas parcialidades e interesses não ultrapassa os limites da análise da disponibilidade de poder e dos fenômenos que podem ser concebidos e explicados como fenômenos da ordem da consciência e/ou da vontade.

Assim, do tratamento dos problemas de interação humana no enfoque estratégico não fazem parte indivíduos ou sujeitos singulares, mas atores políticos (individuais ou coletivos) considerados como tais em virtude dos recursos que controlam (poder), de suas capacidades de organização, de seus projetos políticos (Matus, 1993) e de suas ideologias (Testa, 1986). Ética e vontade, aliadas ao exercício da racionalidade teleológica-instrumental na utilização dos recursos de poder disponíveis, são tu- 
do o que move ou explica o comportamento dos diferentes atores. Desse modo, a subjetividade reconhecida pelo enfoque estratégico como um importante elemento de análise dos processos sociais e de intervenção sobre os mesmos é uma subjetividade restrita (ou identificada) à consciência.

A base essencialmente fenomenológica do conceito de "situação", trabalhado por Matus (1993) como elemento fundamental para a apreensão do significado das ações e das falas dos homens no mundo, ilustra bem essa perspectiva. Se, por um lado, reconhece-se que por trás do que um ator diz ou manifesta reside um "não dito" muito maior - sua situação, na qual o que foi dito ou manifesto se apóia e ganha inteligibilidade -, por outro lado, esse "não dito" é dado por sabido (pelo menos para o ator em questão), pertencendo, portanto, ao mundo dos fenômenos conscientes.

A crença segundo a qual o comportamento dos homens é guiado exclusivamente por fatores conscientes (e por isso conhecidos e passíveis de controle) fica bem evidenciada na pretensão de Matus (1993) de que a situação confira à ação e à linguagem um significado livre de equívocos. Assim, por exemplo, a definição de uma causa (nó explicativo) de um problema deve ter um sentido desprovido de ambigüidade. A ambigüidade e o equívoco constituem o espaço de manifestação do desconhecido, do "erro", da contradição e da incoerência - condições que a consciência procura rejeitar.

Tal compreensão da determinação do comportamento dos indivíduos ou dos atores tem desdobramentos importantes sobre a proposta metodológica do autor para o planejamento. Desse modo, se esse enfoque considera, com base no conceito de situação, a necessidade de uma explicação "policêntrica" da realidade, isto é, que considere as visões presumíveis dos diferentes atores envolvidos, guarda também a expectativa de que é possível se chegar, pela via da construção de consenso, a um sentido único (uma explicação única) e isento de ambigüidade, de ambivalência ou contradição, o que pode ser considerado como extremamente raro ou praticamente impossível nas interações humanas.

Essa perspectiva racionalista, herdada das abordagens positivistas/normativas de planejamento, parece ser congruente com outra crença, relativamente bem desenvolvida no enfoque e igualmente com expressões em sua proposta metodológica, que é a crença na possibilidade de redução da incerteza dos processos sociais e, conseqüentemente, de aumento do grau de controle (ou governabilidade) sobre os mesmos. A rigor, tal pressuposição caracteriza uma das principais contradições nas quais o enfoque estratégico de planejamento e gestão estará irremediavelmente imerso: parte do reconhecimento da complexidade, incerteza e impossibilidade de controle dos processos sociais, mas não pode, pelo próprio caráter instrumental-teleológico inerente a qualquer abordagem de planejamento, deixar de tentar controlá-los. Assim, as análises de cenários, a análise de motivação dos atores, as simulações e todo o restante da análise estratégica não deixam de ser expressões dessas tentativas de controle.

Para que essas análises possam ser minimamente desenvolvidas, algum grau de previsibilidade sobre o comportamento dos atores é necessário, e isso só se obtém partindo-se do pressuposto de que os atores se moverão apenas em função de escolhas racionais. Logo, tanto Matus (1996) como Testa (1986) trabalham com categorias como "vontade", "motivação" e "interesse". Mesmo quando admitem "componentes subjetivos e informais em algum entorno da questão estratégica", que fazem parte do "caráter" das pessoas que pensam a estratégia (Testa, 1986:195) ou, entre os determinantes da ação de um ator, o seu "código de personalidade” (Matus, 1996), estes são identificados com padrões de comportamento e preferências de ordem volitiva.

Uma das principais conseqüências dessa forma de compreensão das interações humanas é o não-reconhecimento dos próprios limites do planejamento e da gestão; a rigor, das práticas de governo. $\mathrm{O}$ espaço de possibilidade de construção da governabilidade estaria demarcado por duas grandes alternativas estratégicas polares: a anulação/aniquilamento do outro (pelo uso da força, da violência) e a construção de um acordo normativo com base em argumentos racionais. Se não se pretende atuar no primeiro pólo, só restam os instrumentos decorrentes do que ainda pode ser considerado um modelo iluminista de política, que supõe possível a obtenção da felicidade humana com base em argumentos racionais e universais.

É preciso, portanto, "desconstruir" tal perspectiva para que se possa melhor explorar os limites, mas também as possibilidades, de construção de projetos coletivos e, no caso das nossas organizações de saúde, voltados para a valorização da vida. Para tanto, uma das primeiras condições é o deslocamento do foco de referência teórica central de um "indivíduo centrado nas necessidades" (racional e "naturalmente" determinadas) para a existência de um "sujeito do desejo e das pulsões” (Birman, 1997:112). 
Um sujeito que manifesta em suas falas e em suas ações não apenas o que é sabido, mas o que ele próprio desconhece e o que é ambíguo e equívoco, que se expressa e se move no mundo segundo (e sobretudo em função de) outras lógicas além da lógica da identidade e da nãocontradição.

A partir daqui, impõe-se a necessidade de revisão da própria concepção de organização, bem como da noção de sujeito e da compreensão dos processos intersubjetivos em seu interior. É o que se busca neste artigo, com o exame das contribuições da abordagem psicossociológica.

\section{A abordagem da psicossociologia}

A psicossociologia é uma vertente da Psicologia Social, que enfoca os grupos, organizações e comunidades em situações cotidianas, utilizando para tal a metodologia da pesquisaação. Com base em seus estudos, são produzidas explicações sobre a criação e evolução do vínculo entre os indivíduos, e também sobre a dinâmica social e seus processos de mudança. No presente trabalho nos limitaremos a enfocar as principais concepções de Eugène Enriquez e André Lévy, dois dos principais autores da psicossociologia francesa contemporânea.

Enriquez (1997) compreende o fenômeno organizacional a partir de suas dimensões cultural, simbólica e imaginária, sendo central a teoria psicanalítica de Freud, incorporando também elementos da filosofia e sociologia contemporâneas, com destaque para o pensamento de Cornelius Castoriadis.

Castoriadis centra sua discussão na possibilidade de autonomia/criatividade dos sujeitos. Ressaltando a anterioridade dos processos sociais com relação ao indivíduo, o qual só existe no interior de uma sociedade e de uma cultura dadas, que lhe são prévias e determinam sua conduta. Assim, toda sociedade tende a produzir indivíduos massificados, conformados a seus valores e ideais, ou seja, heterônomos (Enriquez, 1994a).

No entanto, também com base em de Castoriadis, Enriquez sublinha que os processos sociais são marcados por ambivalências e contradições e que nunca determinam totalmente o comportamento do indivíduo. Enfim, as sociedades e os indivíduos não são totalmente heterônomos. Todo indivíduo pode demonstrar uma parcela de originalidade e autonomia.

Do referencial psicanalítico, a psicossociologia destaca os elementos imaginários presentes e determinantes nos processos sociais e or- ganizacionais. Trata dos processos de identificação, de projeção, de culpabilização, de formação de fantasmas que atravessam a vida dos grupos (Enriquez, 1997).

O que é inovador, na perspectiva psicanalítica, e que vem representar uma ruptura com o pensamento psicológico e mesmo filosófico precedente, é o deslocamento do lugar da verdade do sujeito, apontando como ilusória a idéia de identidade pessoal ou unidade do sujeito e afirmando que os indivíduos são compostos de uma pluralidade de pessoas psíquicas, introduzindo a idéia de um sistema Inconsciente (Enriquez, 1994b). A psicanálise aponta, assim, o descentramento do sujeito, determinado pela sua cisão psíquica, pela convivência de dois registros simultâneos: o da consciência e o do inconsciente, regidos por processos e lógicas distintas, pela pressão de pulsões antagônicas, sobredeterminando seu comportamento.

Dessa forma, o homem passa a ser visto como sujeito clivado, não integrado, atravessado por falhas, desejos, acompanhado por uma inquietante estranheza. Nessa perspectiva, ele estabelece vínculos de identificação com numerosos sujeitos e grupos em um processo que perpassa toda a sua vida.

A incorporação do referencial psicanalítico vai permitir reconhecer e lidar com os fatores inconscientes na vida social e também organizacional, compreendendo-os como fenômenos não simplesmente desconhecidos, mas que atuam de forma indomável, obedecendo a outros processos e princípios (Enriquez, 1997).

A psicanálise vai afirmar, portanto, que existe uma outra cena (a do imaginário, a do inconsciente) que é operante, que afeta a vida psíquica dos indivíduos e grupos. A psicossociologia teria por objetivo, nas palavras do próprio Enriquez, “...elucidar a (ou as) significação(ões), talvez mesmo os sentidos divergentes (ou não-sentidos) que organizam o funcionamento da outra cena" (Enriquez, 1997:29).

Essa abordagem nos obriga a considerar outros elementos, distintos daqueles tradicionalmente tratados pelas teorias organizacionais, para se compreender a possibilidade de ação cooperativa e de desencadeamento de processos de mudança nas organizações. Os processos grupais, a construção de seu imaginário social, de seu sistema de valores comum (representações) e seus respectivos mecanismos de identificação e idealização são elementos centrais.

A identificação é um processo psíquico através do qual um sujeito assimila características do outro, adotando-o como modelo e transformando-se. A personalidade se constitui por su- 
cessivas identificações (Laplanche \& Pontalis, 1986). Esse processo representa um estabelecimento de um laço (investimento) afetivo do indivíduo com o outro. Nesse processo, como observa Freud (1976), há uma espécie de "enriquecimento" do ego com as propriedades do objeto de investimento amoroso. Uma forma importante de identificação reconhecida por Freud (1976), e que constitui a base dos laços que unem os membros de um grupo, é a que se dá por meio da percepção de uma qualidade comum partilhada com outras pessoas e é comandada pelo vínculo que liga cada indivíduo ao líder do grupo.

A idealização é um processo de identificação, no qual as qualidades e o valor do objeto são elevados à categoria de perfeitos (Laplanche \& Pontalis, 1986). É um processo em que ocorre uma tendência de falsificação do julgamento sobre a realidade. Pode ser descrita como uma "fascinação" ou "servidão" pelo objeto (Freud, 1976). Ao contrário da identificação, na idealização ocorreria, segundo Freud (1976), um empobrecimento do ego, que entregou-se ao objeto. Para Enriquez (1994c), a idealização é o mecanismo que permite a toda a sociedade instaurar-se e manter-se, e a todos os indivíduos viverem como seus membros, pois a possibilidade de constituição de qualquer pacto social pressupõe algum nível de idealização sobre o coletivo. Esses processos de idealização implicam, por um lado, uma agressão à singularidade dos indivíduos, que se submetem ao objeto idealizado sem interrogações, mas não deixam de representar também um papel defensivo (Laplanche \& Pontalis, 1986), produzindo certa tranqüilidade e estabilidade psíquica, protegendo os indivíduos contra suas pulsões destrutivas e os seus fantasmas de desintegração.

Esses processos também se verificam no âmbito específico das organizações. Para construção de um projeto comum, é necessário que as representações sobre a organização sejam não apenas intelectualmente pensadas, mas afetivamente sentidas. "Não se trata unicamente de querer coletivamente; trata-se de sentir coletivamente..." (Enriquez, 1994c:57). Esse sentimento, fonte do comportamento grupal, só pode emergir se ligado a um sistema de idealização, fruto de processos conscientes e inconscientes. O processo de idealização é o que dá "consistência, vigor e aura excepcional" tanto ao projeto quanto aos indivíduos, possibilitando sair de sua cotidianidade e partilhar da mesma ilusão (Enriquez, 1994c:57). Todavia, uma idealização maciça da organização pelo indivíduo tem como resultado a perda de autonomia e criatividade dos indivíduos e da própria capacidade de resposta das organizações.

Assim, os grupos e as organizações enfrentam um problema básico, que é o conflito entre o desejo de cada um dos indivíduos de ser reconhecido em sua originalidade e especificidade, de fazer-se aceito em sua diferença e, por outro lado, de ser igualmente reconhecido como um dos membros do grupo e da organização, portanto semelhante aos seus pares, formando um corpo social e não um aglomerado de indivíduos. A forma como uma organização tratará esse conflito imanente pode levar, em seus extremos, a duas alternativas: à massificação, na qual a falta de inovação e inventividade predominam, conformando um projeto comum de caráter monolítico; e à diferenciação, em que o projeto comum admite a expressão de desejos variados e é fruto de argumentações e negociações, sendo a cooperação originada da aceitação e do tratamento dos conflitos. Contudo, essa segunda alternativa, difícil de ser constituída pelo nível de maturidade que exige, pode levar à maximização das contradições e à própria dissolução do grupo ou à constituição de subgrupos, consumindo suas energias na tentativa de elaboração de seus conflitos. Esse quadro aproxima-se da chamada "organização política”, no dizer de Mintzberg (1989), configuração em que a construção de um projeto comum se torna praticamente impossível.

A essa problemática, podem-se acrescentar, considerando-se especificamente a atual conjuntura de desvalorização do setor público e de enfraquecimento do projeto de Reforma Sanitária no Brasil, importantes limitações ao desenvolvimento de processos de idealização envolvendo as organizações públicas de saúde.

À luz dessas questões e focalizando mais especificamente a problemática organizacional, destacam-se, na visão da psicossociologia, elementos que articulam a instância política/social às relações cotidianas, lutas e estratégias dos sujeitos.

Para a psicossociologia “... a organização aparece assim como uma modalidade específica e transitória de estruturação e encarnação da instituição" (Enriquez, 1997:81). Na verdade, uma instituição não existe fora das organizações concretas que ela produz e dá sentido. Assim, se a instituição é o lugar do poder, a organização será o lugar dos sistemas de autoridade (da repartição de competências, de responsabilidades). Dito de outro modo, a organização “... é a transmutação em tecnologia, em 'quinquilharia', da Instituição” (Enriquez, 1997: 81). O termo tecnologia se refere aqui tanto às máquinas, quanto às metodologias e aos pro- 
cedimentos de trabalho, que têm por objetivo estabilizar e canalizar os desejos e os projetos dos diversos grupos e sujeitos na organização.

Nessa perspectiva, Enriquez (1997) recupera a discussão de Alain Touraine sobre a "racionalidade da organização" e privilegia em sua análise a tensão entre o imperativo de rendimento ótimo da máquina e a resistência à reificação dos seres humanos e grupos sociais. Essa compreensão adquire particular importância no momento atual, pois observa-se a utilização abundante de métodos modernos e instrumentos de gestão que tendem a reforçar o aspecto maquinista das organizações e a moldar uma concepção limitada e igualmente simplista dos processos de mudança.

Ao considerar as organizações como estruturações que visam a colocar a ordem em toda parte, Enriquez (1997) nos ajuda a melhor compreender a complexidade dos processos de mudança nas organizações. A partir de uma visão psicanalítica, as organizações são o lugar da compulsão à repetição, característica que expressa uma forma de proteção contra algumas angústias fundamentais que atravessam os grupos e as relações intersubjetivas nas organizações.

Enriquez (1997) apresenta uma concepção geral da organização caracterizando-a como um sistema cultural, simbólico e imaginário. Toda organização dispõe de uma estrutura de valores e de normas que condicionam seus membros a uma certa forma de apreensão do mundo e de orientação de suas condutas. Trata-se de representações sociais historicamente constituídas, resultando na conformação de determinada cultura, que se traduz, por exemplo, “(...) em atribuições de postos, em expectativas de papéis a cumprir, em condutas mais ou menos estabilizadas, em hábitos de pensamento e ação (...)" (Enriquez, 1997:33). Tais representações encontram uma correspondência, do ponto de vista psíquico, sobre os sujeitos que compartilham determinadas imagens sobre as organizações das quais fazem parte - um imaginário social, que deve ser mais ou menos interiorizado por seus membros (Enriquez, 2000).

A organização, nessa perspectiva, é compreendida como uma microssociedade por excelência, e por isso atravessada pelos mesmos problemas que caracterizam o vínculo social (Enriquez, 2000). Toda vida em sociedade é geradora de angústias. Do mesmo modo, a organização luta - a rigor, os indivíduos e grupos em uma organização lutam - contra várias angústias. O medo do "informe”, do caos, é uma delas. Toda a organização se apresenta como "formação" e luta contra a ameaça de um caos desorganizador. Assim, o espontâneo, o imprevisto, os movimentos criadores são vividos, em sua maioria, como “desordens”. Do mesmo modo, a novidade, o desconhecido, podem ser vividos como "fissura".

Outra fonte de angústia, contra a qual as organizações procuram se defender, são as pulsões que atravessam a vida psíquica dos indivíduos e têm seus efeitos na vida social e organizacional. Pulsão é um dos conceitos mais difíceis da Teoria Psicanalítica, tendo sido revisto em vários momentos da obra freudiana. Freud reconheceu a teoria das pulsões como um campo impreciso, representando a mitologia da própria psicanálise. Nos limites permitidos por este trabalho, é possível apenas observar que se trata de um processo dinâmico, que pode se caracterizar como um impulso, carregado de energia e voltado para um objetivo, que em última instância é suprimir um estado de tensão. As pulsões apresentam um caráter limítrofe entre o somático e o psíquico. A pulsão é um representante psíquico de excitações provenientes do corpo e encontra-se na origem do funcionamento psíquico inconsciente do homem (Laplanche \& Pontalis, 1986; Roudinesco \& Plon, 1998). A teoria freudiana sempre apresentou as pulsões de forma dualista e a distinção mais importante é entre pulsão de vida e a pulsão de morte, fundamentais na dinâmica psíquica e na organização da vida social.

As organizações buscam canalizar a pulsão de vida (ou todos os impulsos criativos dos indivíduos) no sentido do trabalho produtivo e dos objetivos organizacionais. Assim, “... adotam como valores sempre a eficiência, $e$ às vezes o dinamismo e a mudança. Tentam então pôr em funcionamento o processo de ligação favorecendo a coesão e a harmonia ..." (Enriquez, 1997:126).

No entanto, a pulsão de vida só tende a ser aceitável quando se dirige para a coesão da organização. Ameaçada pelo fantasma de uma invasão da afetividade e de condutas irracionais, a organização, de certo modo, impede a pulsão de vida de poder se desenvolver. Assim, paradoxalmente, a criatividade tão reclamada e especialmente valorizada pela novas abordagens gerenciais acaba, muitas vezes, refreada.

Além disso, as organizações, enquanto lugar da ordem, da reprodução, também favorecem a expressão da pulsão de morte (enquanto compulsão à repetição), desenvolvendo tendências à homogeneização, à massificação dos indivíduos, à inércia, enfim, à resistência à mudança.

Por outro lado, as organizações tentam se defender contra os impulsos de destruição (ou- 
tra expressão da pulsão de morte) que poderiam atacar seu funcionamento interno (assim, por exemplo, tentam limitar a competição interna, limitando poderes, definindo funções e regras de funcionamento).

Retomando a perspectiva trabalhada por Enriquez, a "organização se instaura, funciona e se estabiliza no interior de um campo pulsional e passional" (Enriquez, 2000:19).

O exposto até aqui permite destacar que uma das principais contribuições da psicossociologia à compreensão dos processos de mudança organizacional é o seu entendimento como um acontecimento que, antes de ser material, objetivo, é psíquico e, portanto, subjetivo.

"O psiquismo (o mental) e sua dinâmica são, então, por excelência, o lugar da mudança, da possibilidade de desligamentos e de novas combinações. As condições materiais, objetivas, só têm valor de mudança quando elas são apropriadas mentalmente ao nível de suas significações." (Levy, 1994a:116)

Na perspectiva da psicossociologia, a mudança se diferencia de um processo evolutivo, de crescimento ou reprodução. Ela se apresenta de modo descontínuo, pressupondo rupturas, reorientações bruscas, redirecionamentos. Mudar é escapar à lei da repetição, é introduzir o inédito, é se abrir a uma história, à aventura (Lévy, 1994a).

A mudança exige então indivíduos criativos, sujeitos autônomos, para resgatar a perspectiva de Castoriadis. As questões abordadas neste texto indicam o equacionamento entre reprodução e criatividade como principal desafio a ser enfrentado nos processos de gestão. Os processos de mudança devem poder promover a inserção de indivíduos criativos em um projeto organizacional (para o qual algum nível de idealização é necessário), sem, contudo, cair na armadilha do controle sutil de seus pensamentos e comportamentos através de uma idealização maciça da organização.

É preciso reconhecer, portanto, que o dilema principal ao qual as organizações estão irremediavelmente imersas é o de, simultaneamente, favorecer a construção de uma identidade coletiva e o exercício da singularidade e da autonomia dos sujeitos.

Fica evidente, pela análise da problemática organizacional aqui realizada, que o indivíduo se liga à organização por vínculos não apenas materiais, mas sobretudo afetivos e imaginários, e que as organizações, embora não criem uma estrutura psíquica, utilizam-se dela. Assim, toda organização é objeto de transferência, não só espontânea, mas também induzida, de afetos, emoções, qualidades e atitudes, po- dendo propiciar a satisfação de necessidades narcísicas dos indivíduos. (Freitas, 1999).

Neste sentido, a tão esperada adesão dos indivíduos ao projeto organizacional pode ser o resultado de dois tipos de processos que, na realidade se apresentam combinados e que são decorrência da produção de um sistema imaginário pela organização. No primeiro caso, a organização se apresenta como a instância central capaz de responder aos desejos narcísicos de reconhecimento e potência dos indivíduos, assegurando proteção contra quebra de suas identidades. Desse modo, tende a substituir o imaginário do indivíduo pelo seu próprio, apresentando-se como superpoderosa e nutriz, aprisionando-o em um "imaginário enganoso" (Enriquez, 1997), que o impossibilita de produção autônoma e criatividade.

Outra possibilidade é a organização engendrar o que Enriquez (1994a) denomina de imaginário motor, favorecendo a criatividade $\mathrm{e}$ sendo capaz de conviver com mudanças e rupturas. Um imaginário que comporta a espontaneidade, a experimentação e o pensamento questionador.

Por ser este um imaginário que abre espaço para o questionamento da própria organização e de suas regras, ele é muito menos desenvolvido que o primeiro (Freitas, 1999). Considerado ainda o contexto de constantes pressões em que as organizações operam, é necessário desde já reconhecer as dificuldades enfrentadas para a instauração de tal processo em seu âmbito. De outra parte, cabe perguntar se a criatividade, o processo de aprendizagem permanente, o aprimoramento contínuo, enfim, o conjunto de inovações e mudanças de que as organizações atualmente necessitam pode efetivamente ser alcançado senão através de tal sorte de arranjo social e humano.

\section{A intervenção psicossociológica}

A organização, como apontamos anteriormente, é o lugar da resistência à mudança, sustentando o pensamento racional e consciente, podendo tornar-se uma estrutura de "solidificação dos seres e das coisas”, facilitando, assim, mais a expressão da pulsão de morte que de vida. Entretanto, ao mesmo tempo a mudança lhe é indispensável. A organização apresenta, na verdade, desejos contrastantes, apontando dessa forma que “... zonas de instabilidade podem descerrar-se” (Enriquez, 1997:290). É exatamente sobre estas zonas que a intervenção vai se concentrar, situando-se na tensão entre resistência e mudança. 
O trabalho da psicossociologia será justamente sobre as resistências, que também podem ser o lugar da mudança. É um trabalho de análise nos níveis organizacional e grupal que busca mudanças não apenas nas estruturas, mas igualmente nos hábitos, atitudes, mentalidades e nos processos psíquicos. O material privilegiado sobre o qual se fará o trabalho de intervenção psicossociológica são as palavras, as representações, as condutas, enquanto efeito de processos inconscientes e intersubjetivos que revelam a organização como espaço de confronto entre sentimentos e fantasias polares, como a angústia e a alegria, os temores de desmembramento e os desejos de onipotência, a identidade individual e coletiva (Enriquez, 1997).

Enriquez (1997) define esse trabalho como um encaminhamento progressivo de sentido, sentido a ser descoberto e construído, com a emergência de novas falas. Tal trabalho se apóia em indagações e, por isso, ele deve permitir a emergência de novos conflitos, provocar uma certa "fratura" no modo de funcionamento da organização.

Essa perspectiva busca questionar, na vida organizacional, o desejo de constituição de um mundo sem conflitos, de uma imagem monolítica da organização, que responde aos anseios de segurança dos sujeitos.

O trabalho de intervenção psicossociológica se inicia a partir da própria análise da demanda, procurando reconstituí-la baseandose em seus sentidos manifestos e latentes, e se centra na discussão de problemas concretos da organização, em grupos de trabalho que visam à livre expressão das pessoas, ao favorecimento de um processo de auto-organização dos vários grupos e sua influência sobre os rumos da organização.

Essa proposta, embora esteja centrada na abordagem psicanalítica, não deixa de valorizar a expressão consciente dos desejos e vontades dos indivíduos e grupos na organização, não pretendendo substituir de imediato sua lógica pela busca de um sentido inconsciente que desvelaria a "verdade" de suas falas e ações, mas ir permitindo a emergência de novas significações que resultam da análise desse material (Enriquez, 1997).

A intervenção psicossociológica pressupõe, simultaneamente a consideração das estruturas psíquicas, e, portanto de suas exigências pulsionais, e das estruturas sociais, com suas dimensões tanto simbólica, quanto política (Nasciutti, 1992). Nessa perspectiva, Enriquez (1997) propõe a articulação de diferentes instâncias de análise das organizações, envolven- do suas dimensões social/histórica, institucional, organizacional, grupal, individual e pulsional. Assim, consideram-se, nas intervenções, tanto as experiências vividas pelos indivíduos e grupos, seus sentimentos e representações que fazem de si mesmo e da organização, como suas estratégias enquanto atores sociais.

Dessa forma, por exemplo, a interrogação sobre a estrutura e a repartição de poder não se esgota numa perspectiva funcional e política, mas avança para uma análise das representações e fantasias, por vezes contraditórias, que “... cada indivíduo, cada grupo tenha da organização, de seus modos de identificação com aquela (e as razões das identificações massivas como das identificações distanciadas), projeções que ele pode ser levado a produzir (projeções que instauram a organização como perseguidora ou ao contrário como o lugar de realização de si mesmo, como um elemento de desenvolvimento)" (Enriquez, 1997:248).

Nesse sentido, a intervenção psicossociológica deve contribuir para que cada um reflita sobre o seu lugar (real e imaginário) na organização e encontre um novo lugar, mas, ao mesmo tempo, deve permitir a interrogação sobre os vínculos que cada um estabelece com ela. Por que a organização nos prende? Por que nos apegamos (ou não) a ela? (Enriquez, 1997)

Essa perspectiva de análise das organizações não deve ser confundida com um processo de psicanálise de grupo nem tampouco com análises individuais no espaço organizacional. Os aportes da psicanálise só são pertinentes para a elaboração das relações que os indivíduos e os grupos estabelecem com a organização e com o poder e para o enfrentamento dos problemas operacionais da organização.

No que diz respeito mais particularmente ao papel do consultor que intervém em uma organização valendo-se da perspectiva psicossociológica, cabe chamar a atenção para a necessidade de um investimento afetivo. Esta perspectiva fica muito bem ilustrada na visão de André Lévy: “... penso que só é possível realizar um trabalho que valha a pena com grupos e organizações quando se tem um interesse afetivo verdadeiro pelas pessoas que fazem parte deles; penso que uma atitude voluntária e falsamente objetiva, desapaixonada, científica, pode ser apenas uma máscara para o desprezo profundo com relação ao outro e representar apenas ações tecnocráticas a serviço de um desejo de poder mais ou menos oculto" (Lévy, 1994b:175).

Outra característica do consultor, na visão de Enriquez (1997), é não se situar em um único lugar. O consultor intervém tanto como analista, quanto como expert, perito no campo or- 
ganizacional. Não há um setting permanente. $\mathrm{O}$ autor também assinala a necessidade de o consultor "... trabalhar com o conjunto do sistema cliente e não com alguns de seus representantes" (Enriquez, 1997:263).

Nessa mesma perspectiva, Lévy (1994a) observa que o consultor não deve estar ligado a nenhum grupo em particular na organização, a não ser transitoriamente. Seu trabalho pode evoluir entre pessoas e grupos e não se restringir à análise de reuniões, mas incluir entrevistas, observações, pesquisa-ação etc. Essa condição é necessária, pois a organização, em seus mecanismos de defesa e resistência à mudança, tende a enquadrar e restringir o trabalho de análise em um lugar determinado, buscando mantê-lo sob controle e, com isso, esvaziandoo de seu significado.

Acima de tudo, o trabalho do consultor deve permitir à organização se perceber como plural e não como um todo homogêneo, compacto, sendo atravessada por conflitos, divisões e alianças. Essa visão se contrapõe ao "fantasma do Uno" que atravessa toda a organização, constituindo um imaginário da organização sem fissuras.

Do exposto até aqui é possível concluir que a intervenção psicossociológica nem sempre irá corresponder às expectativas iniciais daqueles que esperam das intervenções resultados de curto prazo, que estão muito mais ávidos por respostas do que por perguntas e que têm muito pouca tolerância para com a incerteza.

A avaliação dos resultados da intervenção psicossociológica implica considerar o alto grau de incerteza e ambigüidade dos processos sociais, bem como a impossibilidade de se garantir controle sobre os processos de intervenção. Nesse sentido, “...é inevitável que as intervenções tenham resultados ambíguos que podem ser interpretados de maneira muito diferentes, segundo o molde de análise utilizado. Nós queremos determinadas coisas e damos origem a outras. O social é feito assim" (Enriquez, 1997:288).

Sublinhando que as mudanças sociais levam tempo para serem amadurecidas e para se apresentarem como necessárias, traduzindose em condutas concretas, Lévy (1994a) observa que é exatamente o trabalho sobre as resistências e a pulsão de morte que abrirá uma porta essencial para a mudança. São esses aspectos da prática de análise psicossociológica que lhe conferem identidade e a diferenciam das abordagens tecnológicas ou manipuladoras da mudança social.

Em síntese, o objetivo da intervenção psicossociológica pode ser considerado como o de “... ajudar uma instituição que se percebe em estado de crise a se transformar progressivamente numa instituição na qual as capacidades criativas possam superar os conflitos" (Enriquez, 1997:263).

Concluindo, trata-se de um processo vivo, que deve possibilitar o surgimento de novas significações, evitando a cilada do "pensamento herdado", das ilusões sobre a organização.

\section{Considerações finais}

Diante da grave crise de governabilidade, resolutividade e eficiência que as organizações de saúde no Brasil vêm enfrentando, os recémveiculados "valores gerenciais" e as metodologias introduzidas por meio de propostas inovadoras no campo do planejamento e gestão organizacional buscam se apresentar como um caminho para o enfrentamento dos determinantes dessa situação.

O cerne de todas essas experiências inovadoras é gerar o compromisso dos indivíduos com um projeto institucional. Todavia, conforme aqui discutido, as abordagens correntes mostram-se insuficientes para a compreensão da dinâmica entre os indivíduos e as organizações ou para o favorecimento da construção de processos de mudança voltados para a valorização da missão pública das organizações de saúde e capazes, ao mesmo tempo, de possibilitar a autonomia e criatividade de seus profissionais.

$\mathrm{O}$ presente estudo procurou apresentar uma outra perspectiva não só para a análise, como para a intervenção na problemática da relação entre indivíduos e organizações. A importância das contribuições da abordagem psicossociológica francesa para a compreensão das organizações públicas de saúde no Brasil, bem como para a intervenção em seus processos, evidencia-se quando se aprofunda a análise da situação dessas organizações e do contexto em que se inserem.

Palco de manifestação das contradições sociais e dos processos de exclusão e desvalorização da vida que marcam a sociedade brasileira contemporânea, as organizações públicas de saúde vivem uma crise que não é o resultado apenas das políticas de sucateamento e da conseqüente insuficiência de recursos, mas de um complexo processo de desqualificação da assistência que combina omissão, falta de ética, baixa responsabilidade institucional, descompromisso com relação aos processos organizacionais, falta de solidariedade e apatia com relação à dor e ao sofrimento alheios (Sá, 2001). 
Uma outra dimensão dessa crise se apresenta quando se considera mais especificamente o contexto político-institucional brasileiro, especialmente no âmbito público, onde o Estado, ao mesmo tempo em que impõe sobre as organizações públicas um projeto de reforma administrativa, cujos eixos centrais são a privatização e a modernização gerencial, não garante as condições suficientes de financiamento e operação para as suas organizações. Tal situação, uma das fontes do mal-estar que atravessa atualmente essas organizações, representa, por analogia à discussão realizada por Losicer (1995), uma ameaça de morte. Assim, nossas organizações públicas vivem processos de angústia e sofrimento derivados da alta incerteza quanto às suas possibilidades de sobrevivência. Esses processos, longe de favorecerem a mudança, reforçam a resistência, a estereotipia, e as ansiedades paranóides e depressivas nas organizações, aumentando, dessa maneira, a complexidade e os desafios das intervenções organizacionais. É fácil, assim, reconhecer a relevância de um olhar psicossociológico sobre o problema.

A singularidade e inovação da abordagem psicossociológica para a compreensão e intervenção nas organizações se reflete não só no aporte teórico empregado - particularmente a abordagem psicanalítica para elaboração das relações entre os indivíduos e grupos, e para o enfrentamento dos problemas organizacionais - como na própria forma de conceber a intervenção. A intervenção psicossociológica, tal como concebida por Eugène Enriquez, pode ser caracterizada como um trabalho de favorecimento da descoberta e busca contínua de sentidos - social-histórico, institucional/organizacional, grupal, individual e pulsional para as interações humanas nas organizações e, simultaneamente, o que é fundamental des- tacar, de intervenção especializada no campo gerencial.

Tal perspectiva impõe um importante diferencial para a intervenção psicossociológica nas organizações quando comparada a outras propostas de intervenção no campo gerencial. Assim, por exemplo, a intervenção começa pela própria análise do pedido de intervenção e da(s) demanda(s) que o sustenta(m), sendo fundamental a compreensão do cliente como o conjunto dos indivíduos e grupos integrantes da organização, apontando os riscos de se ligar exclusivamente a um determinado grupo. Outro elemento a ser valorizado e que diferencia essa abordagem é o reconhecimento da incerteza quanto aos resultados da intervenção, que é caracterizada, acima de tudo, como um contrato em aberto, em virtude da natureza social do processo organizacional.

Ao mesmo tempo, não se pode desconhecer que a complexidade da abordagem - que considera, ao lado da vontade dos atores e dos problemas estratégicos/operacionais da organização, os processos inconscientes que a atravessam - pode dar origem a práticas simplificadoras, restritas a uma dimensão reflexiva e pedagógica, não diferenciadas de outras tantas abordagens manipuladoras de "gestão pelo afetivo”. De outra parte, não se pode deixar de considerar que é essencial o desenvolvimento de experiências concretas de aplicação dessa abordagem em organizações de saúde no País, que possam aprofundar, no plano empírico, a avaliação sobre seus limites e possibilidades.

O presente trabalho procurou demonstrar que há um grande potencial de contribuição da abordagem psicossociológica para as organizações públicas de saúde no Brasil e sua discussão e aplicação é algo que não pode prescindir do diálogo e articulação com outros aportes e experiências do campo da gestão. 


\section{Referências}

BIRMAN, J., 1997. Estilo e Modernidade em Psicanálise. São Paulo: Editora 34.

BRAVERMAN, H., 1980. Trabalho e Capital Monopolista: A Degradação do Trabalho no Século XX. Rio de Janeiro: Zahar Editores.

DE COCK, C. \& HIPKIN, I., 1997. TQM and BPR: Beyond the beyond myth. Journal of Management Studies, 34:659-675.

DEMING, W. E., 1990. Qualidade: A Revolução da Administração. Rio de Janeiro: Editora Marques Saraiva.

ENRIQUEZ, E., 1994a. O papel do sujeito humano na dinâmica social. In: Psicossociologia: Análise Social e Intervenção (A. Lévy, A. Nicolaï, E. Enriquez \& J. Dubost, org.), pp. 24-40, Petrópolis: Editora Vozes.

ENRIQUEZ, E., 1994b. A interioridade está acabando? In: Psicossociologia: Análise Social e Intervenção (A. Lévy, A. Nicolaï, E. Enriquez \& J. Dubost, org.), pp. 41-55, Petrópolis: Editora Vozes.

ENRIQUEZ, E., 1994c. O vínculo grupal. In: Psicossociologia: Análise Social e Intervenção (A. Lévy, A. Nicolaï, E. Enriquez \& J. Dubost, org.), pp. 56-69, Petrópolis: Editora Vozes.

ENRIQUEZ, E., 1997. A Organização em Análise. Petrópolis: Editora Vozes.

ENRIQUEZ, E., 2000. Vida psíquica e organização. In: Vida Psíquica e Organização (P. Motta \& M. E. Freitas, org.), pp. 11-22, São Paulo: Editora Fundação Getúlio Vargas.

FREITAS, M. E., 1999. Cultura Organizacional: Identidade, Sedução ou Carisma? São Paulo: Editora Fundação Getúlio Vargas.

FREUD, S., 1976. Psicologia de Grupo e Análise do Ego. Rio de Janeiro: Editora Imago.

GARVIN, D. A., 1988. Managing Quality. New York: Free Press.

HACKMAN, J. R. \& WAGEMAN, R., 1995. Total quality management: Empirical, conceptual and pratical issues. Administrative Science Quartely, 40:309342.

JURAN, J. M. \& GRYNA, F. M., 1991. Juran: Controle de Qualidade Handbook. São Paulo: Editora McGrawHill.

LAPLANCHE, J. \& PONTALIS, J. B., 1996. Vocabulário da Psicanálise. São Paulo: Editora Livraria Martins Fontes.

LÉVY, A., 1994a. A mudança: Este obscuro objeto do desejo. In: Psicossociologia: Análise Social e Intervenção (A. Lévy, A. Nicolaï, E. Enriquez \& J. Dubost, org.), pp. 113-124, Petrópolis: Editora Vozes.

LÉVY, A., 1994b. Intervenção como processo. In: Psicossociologia: Análise Social e Intervenção (A. Lévy, A. Nicolaï, E. Enriquez \& J. Dubost, orgs.), pp. 174-198, Petrópolis: Editora Vozes.
LOSICER, E., 1995. A pro-cura da subjetividade: A organização pede análise. In: Recursos Humanos e Subjetividade (E. Davel \& J. Vasconcellos, org.), pp. 68-79, Petrópolis: Editora Vozes.

MATUS, C., 1993. Política, Planejamento e Governo. Brasília: Instituto de Pesquisas Econômicas e Aplicadas.

MATUS, C., 1996. Estratégias Políticas: Chimpanzé, Machiavel e Gandhi. São Paulo: Fundação do Desenvolvimento Administrativo do Estado de São Paulo.

MINTZBERG, H., 1989. Mintzberg on Management: Inside our Strange World of Organizations. New York: Free Press.

McARDLE, L.; ROWLINSON, M.; PROCTER, S.; HASSARD, J. \& FORRESTER, P., 1995. Total quality management and participation. In: Making Quality Critical: New Perspectives on Organizational Change (A. Wilkinson \& H. Wilmott, ed.), pp. 156172, London: Routledge.

NASCIUTTI, J., 1992. Reflexões sobre o Espaço da Psicossociologia. Rio de Janeiro: Universidade Federal do Rio de Janeiro. (mimeo.)

NOGUEIRA, R. P., 1994. Perspectivas da Qualidade em Saúde. Rio de Janeiro: Qualitymark.

SÁ, M. C., 2001. Subjetividade e projetos coletivos: Mal-estar e governabilidade nas organizações de saúde. Ciência \& Saúde Coletiva, 6:151-164.

SCHIFF, G. D. \& GOLDFIELD, N. I., 1994. Deming meets Braverman: Toward a progressive analysis of the continuous quality improvement paradigm. International Journal of Health Services, 24:655-673.

SULLIVAN, J. J., 1986. Human nature, organizations and management theory. Academy of Management Review, 11:534-549.

ROUDINESCO, E. \& PLON, M., 1998. Dicionário de Psicanálise. Rio de Janeiro: Jorge Zahar Editor.

TESTA, M., 1986. Pensamiento Estratégico y Lógica de Programación: El Caso de Salud. Buenos Aires: Organizacion Panamericana de la Salud.

TURCHI, L. M., 1997. Qualidade Total: Afinal do que Estamos Falando? Texto para Discussão 459. Brasília: Instituto de Pesquisas Econômicas e Aplicadas.

WILKINSON, A. \& WILMOTT, H., 1995. Making Quality Critical: New Perspectives on Organizatinal Change. London: Routledge.

Recebido em 21 de agosto de 2000

Versão final reapresentada em 19 de março de 2001

Aprovado em 14 de agosto de 2001 